\title{
Developing an Intelligent e-Restaurant with a Menu Recommender for Customer-centric Service using Wi-Fi Technology
}

\author{
P.V.Gayatri \\ Dept.of ECE \\ Vardhaman College of Engg \\ M.Tech Student \\ Hyderabad, India
}

\author{
J.Krishna chaitanya \\ Dept.of ECE \\ Vardhaman College of Engg \\ Associate Professor \\ Hyderabad, India
}

\author{
K.Harikrishna, Ph.D \\ Dept.of ECE \\ Vardhaman College of Engg \\ Professor \\ Hyderabad, India
}

\begin{abstract}
The existing system suggests that of serving in restaurant do not appear to be completely digitized, still a consumer need to be compelled to observe for server to supply his order list that unit on the market among the menu card. This truly takes ton overabundant time and man power in addition there can also be heap of inconvenience to the consumers to attend. Therefore thus on prune the work load and to provide consumer satisfaction this system is enforced.
\end{abstract}

\section{Keywords}

RFID module, embedded platform, communication module, GSM module, WIFI module

\section{INTRODUCTION}

In a general building the service method from reservation, creating order from the menu, and delivery of meal to paying the bill, needs waiter to create notes consistent with every customer's order so transmit them to the room for preparation. Once client pays the bill, the quantity due is additionally calculated by the cashier consistent with the note. although such a way is incredibly easy, it's going to considerably increase the work of waiters suddenly will increase throughout eating hours; so seriously degrading overall service quality. Therefore, a way to effectively improve the service quality for purchasers by victimization advanced technologies has received a lot of attention in recent years [13].as an example, the counter system of the many victuals restaurants in Taiwan is provided with a touch-screen, computer keyboard or mouse management interface for cashier to handle customer's desires. This sort of system typically has the common purpose of Sale (POS) perform, that permits waiters to use associate optical scanner to directly browse the second barcode for order details and total charge.

However, with this technique the waiter will solely deals with every order on POS system by asking customers want so waits for answer? Therefore, solely passive services are often provided. However, a top quality service system ought to be customer-centred, i.e., customer's identity therefore his/her favourite meals and expenditure records in past days are often now recognized by service system so on offer customercentric services. to attain this goal, this study can integrate RFID Associate in Nursing wireless native space network (WLAN) technologies to implement an e-restaurant for customer-centric service, that permits waiters to right away establish every client via his/her own RFID-based card then actively offer custom-built services. Also, customers will use the RFID-based card to pay the bill rather than victimisation money. Moreover, to facilitate waiter's board service, this analysis develops moveable service unit on personal digital assistant (PDA).. Also, the expenditure data are often sent to the counter for pre-processing of bill. The eating place managers will access to the information for mastering the business standing anytime and creating acceptable predisposition for food materials. it's worthy to notice that each one the order data and expenditure contents are digitalized to store within the database; that permits eating place homeowners to think about adequate discounts or promoted service to customers supported expenditure statistics. Customers can so appreciate top quality service and therefore the image and business revenue of the restaurants may be considerably increased. The remainder of this paper is organized as follows. In Section two, literature review together with RFID technology is introduced. Associate in nursing e-restaurant for customer-centric service is conferred in Section three. Section four describes the implementation of a wireless ordering system.

\subsection{Block diagram}

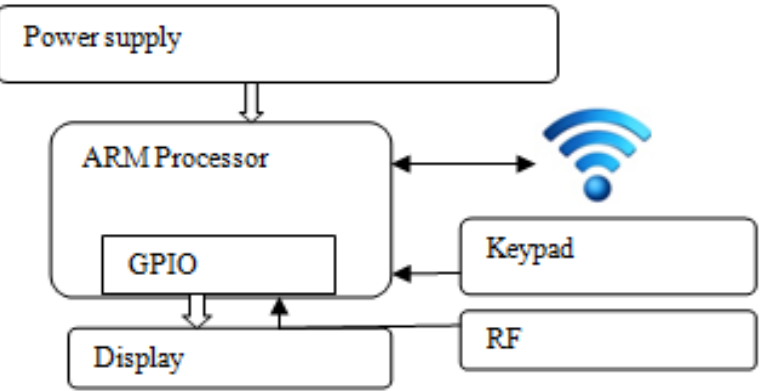

Figure 1.Table Section

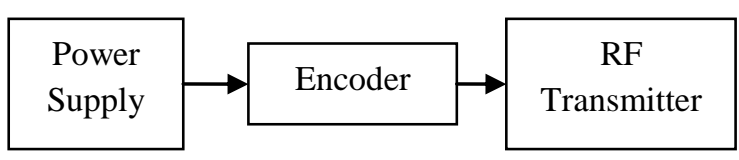

Figure 2.Feedback Section 


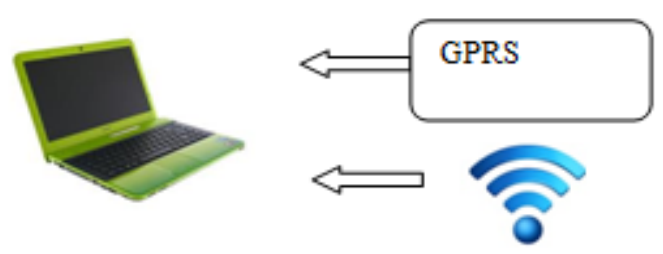

Figure 3.Billing Section

\section{SYSTEM HARDWARE}

\subsection{ARM Processor}

The ARM7 family includes the ARM7TDMI, ARM7TDMI-S, ARM720T, and ARM7EJ-S processors. The ARM7TDMI core is that the industry's most generally used 32-bit embedded RISC micro chip resolution. Optimized for value and power-sensitive applications, the ARM7TDMI resolution provides the low power consumption, small size, and high performance required in transportable, embedded applications. The ARM7TDMI core uses a three-stage pipeline to extend the flow of directions to the processor. This enables multiple coincidental operations to require place and continuous operation of the process and memory systems. Because the processor has a high speed it's simple to form the communication between the RF module and therefore the Image acquisition module

\subsubsection{Operating modes:}

The ARM7TDMI core has seven modes of operation:

- User mode is that the usual program execution state Interrupt (IRQ) mode is employed for general purpose interrupt handling

- Supervisor mode may be a protected mode for the package

- Abort mode is entered once an information or instruction pre fetch abort

- The interrupt setting of ARM supports the DHLS to response to the interrupt returning from the server section.

\subsubsection{Interrupt controller:}

The Vectored Interrupt Controller (VIC) accepts all of the interrupt request inputs from the house server section and categorizes them as quick Interrupt Request (FIQ), vectored Interrupt Request (IRQ), and non-vectored IRQ as outlined by programmable settings. These interrupt settings can offer a quick response to the RF decoder. so address verification are going to be terribly quicker and signal for image process are going to be given to the image acquisition module.

\subsubsection{Wireless communication:}

\subsubsection{RF communication:}

Frequency, any frequency at intervals the spectrum related to radio emission propagation. once $\mathrm{AN}$ RF current is equipped to AN antenna, AN magnetism field is made that then is ready to propagate through house. Several wireless technologies area unit supported RF field propagation.

\subsubsection{Transmitter:}

The TWS-434 extraordinarily tiny, and area unit wonderful for applications requiring short-range RF remote controls. The TWS-434 modules don't incorporate internal encryption. If straightforward management or standing signals like button presses or switch closures need to send, think about employing AN encoder and decoder IC set that takes care of all encryption, error checking, and secret writing functions.
The transmitter output is up to $8 \mathrm{~mW}$ at $433.92 \mathrm{MHz}$ with a range of approximately 400 foot (open area) outdoors. Indoors, the range is approximately 200 foot, and will go through most walls. The TWS-434 transmitter accepts both linear and digital inputs can operate from 1.5 to 12 Volts-DC, and makes building a miniature hand-held RF transmitter very easy.

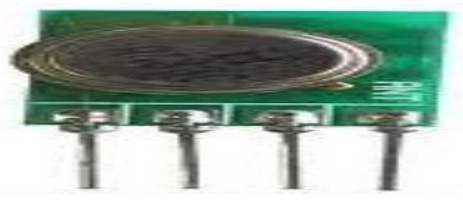

Figure 4. RF Transmitter

\subsubsection{3. $R F$ receiver:}

RWS-434: The receiver conjointly operates at $433.92 \mathrm{MHz}$, and encompasses a sensitivity of $3 \mathrm{uV}$. The WS-434 receiver operates from four. 5 to 5.5 volts-DC, and has each linear and digital output.

A zero potential unit to Vcc information output is accessible on pins. This output is often accustomed drive a digital decoder IC or a microchip that is acting the info decryption. The receiver's output can solely transition once valid information is gift. In instances, once no carrier is gift the output can stay low.

The RWS-434 modules don't incorporate internal decryption. If you wish to receive easy management or standing signals like button presses or switch closes, you'll be able to use the encoder and decoder IC set delineated higher than. Decoders with fugitive and bolted outputs are obtainable.

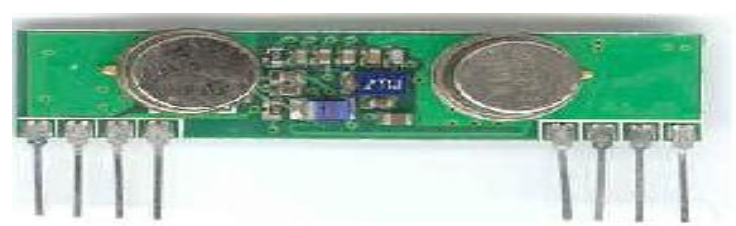

Figure 5.RF Receiver

\subsection{Data Transfer Scheme}

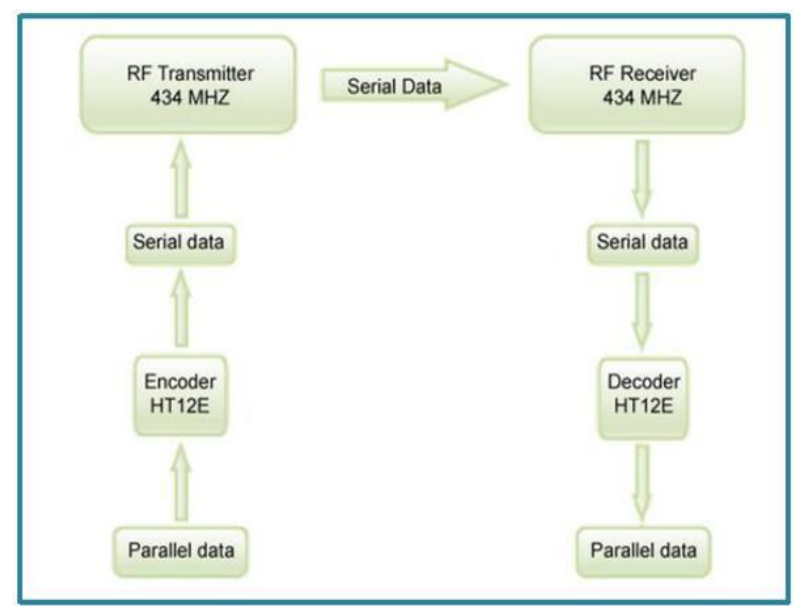

Figure 6. Data Transfer Scheme 


\subsection{GSM Module}

GSM electronic equipment could be wireless electronic equipment that works with a GSM wireless network. World system for mobile communication (GSM) could be a globally accepted customary for digital cellular communication. GSM is that the name of a customarization cluster established in 1982 to form a standard European mobile phone standard that will formulate specifications for a pan-European mobile cellular radio system operational at 900 rates.

GSM provides recommendations, not needs. The GSM specifications outline the functions and interface needs well however don't address the hardware. the rationale for this can be to limit the designers as very little as doable however still to form it doable for the operators to shop for instrumentality from totally different suppliers. The GSM network is split into 3 major systems: the change system (SS), the bottom station system (BSS), and therefore the operation and network (OSS). The essential GSM network components are shown in below figure.
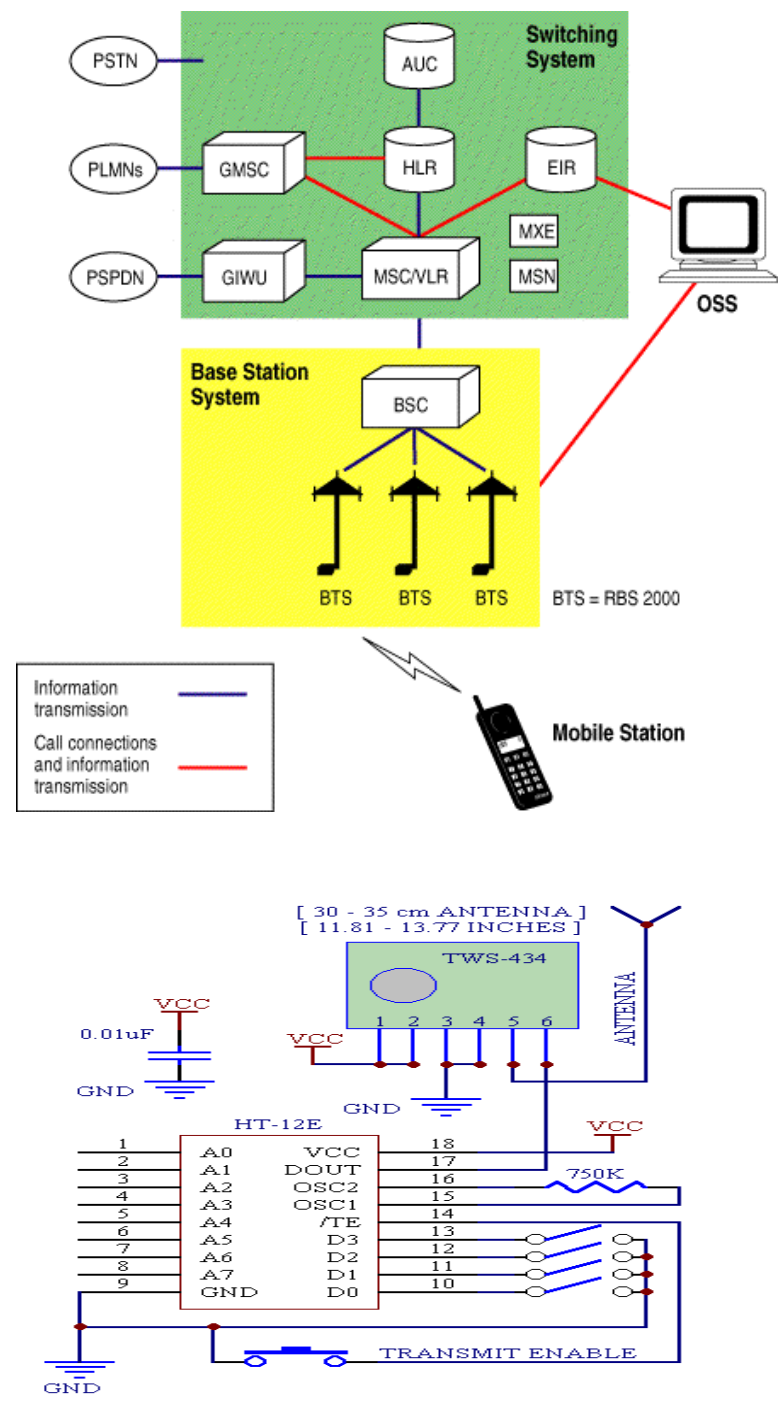

Figure 7.GSM Module

GSM modems support AN extended set of AT commands. These extended AT commands are outlined within the GSM standards. With the extended AT commands, you'll be able to do things like:

- $\quad$ Reading, writing and deleting SMS messages.

- $\quad$ Sending SMS messages.

- monitoring the signal strength.

- Monitoring the charging standing and charge level of the battery.

- $\quad$ Reading, writing and looking phone book entries.

\section{Sending the message}

To send the SMS message, kind the subsequent command:

$\mathrm{AT}+\mathrm{CMGS}="+31638740161 "$

Replace the higher than variety telephone number|number|signal|signaling|sign $\}$ together with your own telephone number. The electronic equipment can respond with:

\&gt; (Response from the modem)

You can currently kind the message text and send the message victimization the - key combination:

\section{Hello World!}

Here CTRL-Z is keyword for causing AN sms through the mobile device. After some seconds the electronic equipment can respond with the message ID of the message, indicating that the message was sent correctly: +CMGS: 62

\subsection{WIFI Module}

$\mathrm{Wi}-\mathrm{Fi}$, also spelled $\mathrm{Wi}-\mathrm{Fi}$ or $\mathrm{Wi}-\mathrm{Fi}$, is a local area wireless technology that allows an electronic device to exchange data or connect to the internet using $2.4 \mathrm{GHz}$ UHF and $5 \mathrm{GHz}$ SHF radio waves. The name is a trademark name, and is a play on the audiophile term Hi-Fi. The Wi-Fi Alliance defines Wi-Fi as any "wireless local area network (WLAN) products that are based on the Institute of Electrical and Electronics Engineers' (IEEE) 802.11 standards".[1] However, since most modern WLANs are based on these standards, the term "Wi-Fi" is used in general English as a synonym for "WLAN". Only Wi$\mathrm{Fi}$ products that complete Wi-Fi Alliance interoperability certification testing successfully may use the "Wi-Fi CERTIFIED" trademark.

Many devices can use Wi-Fi, e.g., personal computers, videogame consoles, smart phones, some digital cameras, tablet computers and digital audio players. These can connect to a network resource such as the Internet via a wireless network access point. Such an access point (or hotspot) has a range of about 20 meters (66 feet) indoors and a greater range outdoors. Hotspot coverage can comprise an area as small as a single room with walls that block radio waves, or as large as many square kilometers achieved by using multiple overlapping access points.

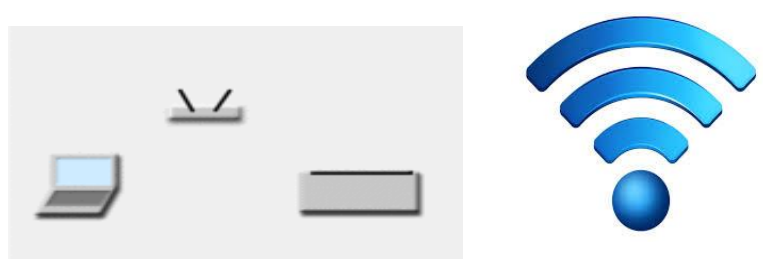

Figure 8. WIFI Module 
Depiction of a device sending information wirelessly to another device both connected to the local network, in order to print a document.Wi-Fi can be less secure than wired connections (such as Ethernet) because an intruder does not need a physical connection. Web pages that use SSL are secure but unencrypted internet access can easily be detected by intruders. Because of this, $\mathrm{Wi}-\mathrm{Fi}$ has adopted various encryption technologies. The early encryption WEP, proved easy to break. Higher quality protocols (WPA, WPA2) were added later. An optional feature added in 2007, called Wi-Fi Protected Setup (WPS), had a serious flaw that allowed an attacker to recover the router's password.[2] The Wi-Fi Alliance has since updated its test plan and certification program to ensure all newly certified devices to resist attacks.

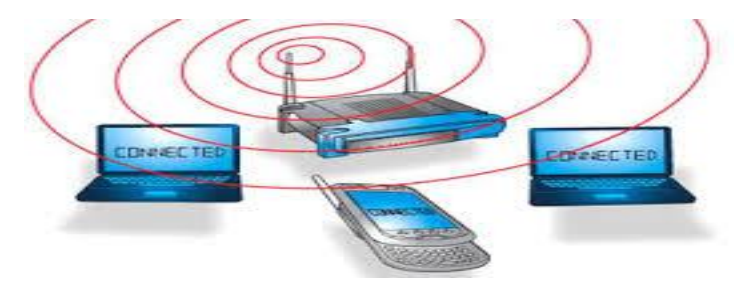

Figure 9.WIFI Communication

\subsection{RECEIVER SECTION FLOW CHART}

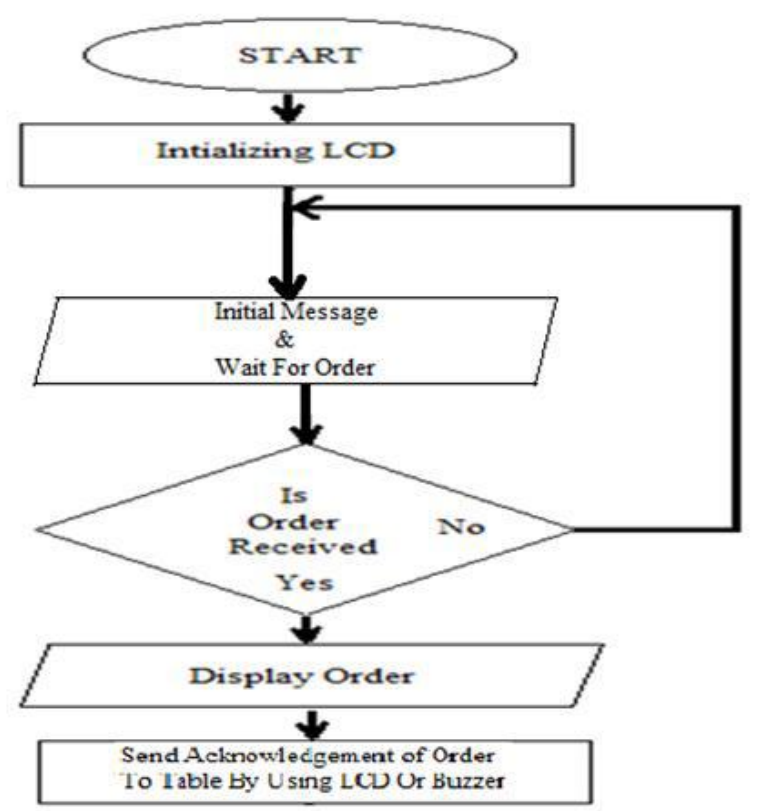

Figure 10. Design flow

\subsubsection{Design Flow:}

The design flow of this project is first we need to initialize the display unit. And by using GSM technology we will receive a sms after message receiving wait up to order. When the order is received display the order on the display unit. And send that order to the restaurant section by using display unit part.

\section{CONCLUSION}

$\mathrm{E}$ restaurant is developed in order to provide easy interaction between customers through wireless technology. Customers will get a reply message of available menu items when he sends an enquiry message. With the keypad (at every table) the customers can order their items, these messages are sent to the cashier section wirelessly where he acknowledges with the total amount for the order. This amount (acknowledgment) will be displayed on the LCD at the respective Table section

\section{REFERENCES}

[1] C. C. Chao, J. M. Yang, and W. Y. Jen, "Determining technology trends and forecasts of RFID by a historical review and bibliometric analysis from 1991 to 2005," Technovation, vol. 27, no. 5, pp. 268-279, 2007.

[2] M. Tajima, "Strategic value of RFID in supply chain management," J. Purchasing Supply Manage., vol. 13, no. 4, pp. 261-273, 2007.

[3] Y. Xiao, X. Shen, B. Sun, and L. Cai, "Security and privacy in RFID and applications in telemedicine," IEEE Common. Mag., vol. 44, no. 4, pp. 64-72, Apr. 2006.

[4] E. Budak, B. Catay, I. Tekin, H. Yenigun, M. Abbak, S. Drannikov, and O. Simsek, "Design of an RFID-based manufacturing monitoring and analysis system," in Proc. IEEE Int. Conf. RFID Eurasia, Sep. 2007, pp. 1-6.

[5] T. Reisbacka, H. Hamalainen, and J. Ikonen, "Automating construction project quality assurance with RFID and mobile technologies," in Proc. IEEE Int. Conf. Softw., Telecomm. Compute. Newt., Sep. 2008, pp.

[6] T. H. Tan, T. Y. Liu, and C. C. Chang, "Development and evaluation of an RFID-based ubiquitous learning environment for outdoor learning," Interactive Learning Environments, vol. 15, no. 3, pp. 253-269, 2007.

[7] M.Montaner, B. Lopez, and J. L. D. Rosa, "A taxonomy of recommender agents on the internet," Artif. Intell. Rev., vol. 19, no. 4, pp. 285-330, 2003.

[8] S. H. Choi, Y. S. Jeong, and M. K. Jeong, "A hybrid recommendation method with reduced data for largescale application," IEEE Trans. Syst Man, Cybern. C, Appl. Rev., vol. 40, no. 5, pp. 557-566, Sep. 2010.

[9] Y. F. Wang, D. A. Chiang, M. H. Hsu, C. J. Lin, and I. L. Lin, "A recommender system to avoid customer churn: A case study," Expert Syst. Appl., vol. 36, no. 4, pp. 8071-8075, 2009.

[10] P. Y. Ekel, J. S. C. Martini, and R. M. Palhares, "Multicriteria analysis indecision making under information uncertainty," Appl. Math. Computvol. 200, no. 2, pp. 501-516, 2008.

[11] S. M. Chen and C. H. Wang, "A generalized model for prioritized multicriteriadecision making systems," Expert Syst. Appl., vol. 36, no. 3,pp. 4773-4783, 2009.

[12] B. Malakooti, "Identifying no dominated alternatives with partial information for multiple-objective discrete and linear programming problems,'IEEE Trans. Syst., Man, Cyber., vol. 19, no. 1, pp. 95-107, Jan./Feb.1989.

[13] B. S. Ahn, "Multiattribute decision aid with extended ISMAUT," IEEETrans. Syst., Man, Cybern. A, Syst. Humans, vol. 36, no. 3, pp. 507-520,May 2006. 